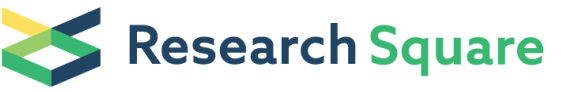

\section{Amplification of Elevation-Dependent Temperature Variability Since the Last Glacial Maximum}

Fenglin Lü

Institute of Tibetan Plateau Research, Chinese Academy of Sciences

\section{Zhe Sun}

Institute of Tibetan Plateau Research, Chinese Academy of Sciences

\section{Kan Yuan}

Institute of Tibetan Plateau Research, Chinese Academy of Sciences

Xiaohuan Hou

Institute of Tibetan Plateau Research, Chinese Academy of Sciences

\section{Mingda Wang}

Liaoning Normal University https://orcid.org/0000-0002-8081-755X

\section{Jun Cheng}

Nanjing University of Information Science and Technology https://orcid.org/0000-0003-0168-1410

\section{Xianyong Cao}

Institute of Tibetan Plateau Research, Chinese Academy of Sciences

\section{Wei Ding}

Free University of Berlin

\section{Elena Xoplaki}

Justus-Liebig-Universität Gießen https://orcid.org/0000-0002-2745-2467

\section{Jürg Luterbacher}

World Meteorological Organization

Juzhi Hou ( $\nabla$ houjz@itpcas.ac.cn )

Institute of Tibetan Plateau Research Chinese Academy of Sciences https://orcid.org/0000-0002-8512-

5739

\section{Fahu Chen}

Institute of Tibetan Plateau Research, Chinese Academy of Sciences https://orcid.org/0000-00028874-1035

\section{Article}

Keywords: Elevation-Dependent Warming, Last Glacial Maximum, Elevation-Dependent Temperature Amplification

Posted Date: August 10th, 2021 
DOI: https://doi.org/10.21203/rs.3.rs-622682/v1

License: (c) (1) This work is licensed under a Creative Commons Attribution 4.0 International License. Read Full License 
1 Amplification of Elevation-Dependent Temperature Variability Since the Last

2 Glacial Maximum

4 Fenglin Lü ${ }^{1}$, Zhe Sun ${ }^{1,2}$, Kan Yuan ${ }^{1,2}$, Xiaohuan Hou ${ }^{1,2}$, Mingda Wang ${ }^{3}$, Jun Cheng ${ }^{4}$,

5 Xianyong Cao ${ }^{1}$, Wei Ding ${ }^{5}$, Elena Xoplaki ${ }^{6,7}$, Jürg Luterbacher ${ }^{8}$, Juzhi Hou ${ }^{1 *}$, Fahu

6 Chen $^{1 *}$

$8 \quad{ }^{1}$ State Key Laboratory of Tibetan Plateau Earth System and Resources Environment

9 (TPESRE), Institute of Tibetan Plateau Research, Chinese Academy of Sciences, Beijing

10 100101, China

$11{ }^{2}$ University of Chinese Academy of Sciences, Beijing 100039, China

$12{ }^{3}$ School of Geography, Liaoning Normal University, Liaoning 116029, China

$13{ }^{4}$ School of Atmospheric Sciences, Nanjing University of Information Science \&

14 Technology, Nanjing 210044, China

$15{ }^{5}$ Institute of Geological Sciences, Palaeontology, Free University of Berlin, Berlin 12249,

16 Germany

$17{ }^{6}$ Department of Geography, Climatology, Climate Dynamics and Climate Change, Justus

18 Liebig University Giessen, Germany

$19{ }^{7}$ Centre for International Development and Environmental Research, Justus Liebig

20 University Giessen, Germany 
$21{ }^{8}$ Science and Innovation Department, World Meteorological Organization (WMO),

22 Geneva, Switzerland

23

24 Corresponding authors: Prof. Juzhi Hou, houjz@itpcas.ac.cn, Prof. Fahu Chen,

25 fhchen@itpcas.ac.cn

26

27 The mechanisms of recent Elevation-Dependent Warming (EDW) remain debated

28 because nearly all data sources are limited to past decades and subject to

29 anthropogenic effects. Here, we study how temperature changed along the elevation

30 gradient around the world since the Last Glacial Maximum (LGM) and aim to shed

31 lights on the mechanisms of EDW and implications for the future climate change in

32 alpine regions. We present a unique network of 192 quantitative terrestrial

33 temperature records along elevation gradient up to $\sim 5000 \mathbf{m}$ to study the past

34 Elevation-Dependent Temperature Amplification (EDTA) since LGM. EDTA is

35 exemplified by much stronger temperature variability at high-elevation sites during

36 climate transitions of millennial- to centennial-scales. The spatiotemporal patterns

37 of EDTA indicate that the surface albedo, caused by changes in glacier and

38 vegetation coverage, played the most important role, which resulted in steeper lapse

39 rate during the LGM and flatter in the Mid-Holocene. This suggests that alpine

40 regions experienced much colder environments in glacial and much warmer in 
41 interglacial periods. This also implies that the mountain regions would warm much

42 faster in the context of current global change. The study emphasizes the need to

43 reassess and reevaluate alpine climate change mechanisms, and to reconsider the

44 mitigation and adaptation implementation strategies under the future global

45 warming scenarios.

There is growing consensus from meteorological observations, reanalysis data,

48 remotely sensed imagery, and climate models that the high-elevation regions have

49 experienced accelerated warming compared to low-elevation environments over past

50 decades, known as the Elevation-Dependent Warming (EDW). EDW severely affects the

51 stability of alpine cryosphere and ecosystems ${ }^{1,2}$ and has been reported in alpine regions

52 with elevation higher than $500 \mathrm{~m}$ above sea level (a.s.1), including the High Mountain

53 Asia, Rocky Mountains, Andes Mountains, Kilimanjaro and European Alps etc ${ }^{1}$. The

54 Tibetan Plateau (TP), for example, the highest and largest highland on earth, has

55 experienced much faster warming than the global average in recent decades ${ }^{3,4}$, with more

56 evident warming in winter, followed by mean annual temperature, and summer

57 temperature ${ }^{5}$. Further, tree-ring width and maximum latewood density from the TP

58 suggests that the onset of a decrease in summer-to-winter temperature difference started

59 in the $1870 \mathrm{~s}^{6}$. These changes may have increased spring-summer precipitation and

60 intensified the hydrological cycle, increased glacier instability and associated hazards ${ }^{7}$, 
61 posing severe threats to freshwater resources in the South and East Asia ${ }^{8,9}$. It may imply

62 also a highly climate instability that might affect the Asia's water towers for the global

63 mean warming of $1.5-2{ }^{\circ} \mathrm{C}$ (the Paris Agreement climate target) and much higher

64 warming rates above pre-industrial levels at the end of the twenty-first century.

65

66 A series of factors have been proposed as mechanisms for the EDW, including

67 snow-albedo feedback, cloud-radiation, as well as water vapor and radiative fluxes, via

68 monitoring net flux of energy to the surface along an elevation gradient ${ }^{1}$. However, due to

69 few available data sources, the short-term observational evidence in the context of high

70 anthropogenic greenhouse gas emission may hamper in-depth understanding of the

71 mechanisms for EDW, which makes it an open question. A large number of terrestrial

72 temperature reconstructions and syntheses have been reported since the $\mathrm{LGM}^{10-15}$, which

73 provide a unique opportunity to assess past changes in temperature along elevation

74 gradients at various time and space scales spanning the past 21 thousand years. A

75 previous study focused on four lakes at different elevations on Mt. Kenya (East Africa)

76 found that the lapse rate was significantly steeper at the Last Glacial Maximum (LGM)

77 compared to modern times ${ }^{16}$. This implies that the alpine regions may have experienced a

78 much colder climate than lower elevations. Here, we use a unique paleoclimatic dataset

79 of quantified terrestrial temperature reconstructions to study the past changes in

80 temperature along elevation gradient around the world since the LGM. We aim to study 
81 the Elevation-Dependent Temperature Amplification (EDTA) at climate transitions on

82 orbital-, millennial-, and centennial- scales, including LGM to the Holocene Thermal

83 Maximum (HTM), HTM to the Late Holocene (LH), the Medieval Climate Anomaly

84 (MCA) to Little Ice Age (LIA), and compare with modern EDW.

85

86 Data and Methods

87 We compiled three global datasets consisting of 192 quantitative terrestrial

88 temperature records since the LGM. We selected quantitative temperature reconstructions

89 with precise age controls, high temporal resolution, and explicit temperature implications

90 that cover different intervals. The dataset includes temperature records from long chain

91 alkenones (LCAs), glycerol dialkyl glycerol tetraethers (GDGTs), chironomidae (midge),

92 and pollen (Fig. 1, Methods and Supplementary Data). There are 30 records covering the

93 transition of LGM-HTM, with elevation range of 0-3194 meters above sea level (m

94 a.s.1.), 126 records at the HTM-LH period with elevation range of 0-5059 $\mathrm{m}$ a.s.1., and 36

95 records for the MCA-LIA with elevation range of 54-4450 $\mathrm{m}$ a.s.1., respectively (see

96 Methods and Supplementary Data). The original temperature reconstructions were not

97 recalibrated due to the lack of global transfer functions for each proxy indicator.

98 According to the original publications, $\sim 39 \%$ of the records reflect annual mean

99 temperature, and $\sim 61 \%$ reflect summer temperature (Supplementary Dataset 1 ). For all

100 records we calculated the temperature change across the three transitions by averaging 
101

102

103

104

105

106

107

108

109

110

111

112

113

114

115

116

117

temperature at time slices of 1000 years for LGM, HTM, LH, and 300 years for MCA and LIA (Figure S1) using a moving average-based slide window algorithm. We also calculated the lapse rate for temperature reconstructions at LGM, HTM and LH, in order to compare with modern observations (see details in Supplementary Methods).

\section{Results and Discussion}

Records at high-elevation sites show much larger amplitudes of temperature variability than low-elevation during transitions of different timescales, including the LGM-HTM at orbital scale, the HTM-LH at millennial scale, and the MCA-LIA at centennial scale (Fig 2 and Fig. S3). Temperature differences $(\Delta T)$ for all records between LGM and HTM ( $\left.\Delta T_{L G M-H T M}\right)$, HTM and LH $\left(\Delta T_{H T M-L H}\right)$, MCA and LIA $\left(\Delta T_{M C A-L I A}\right)$ were plotted against the elevation (Fig. S3). The composite dataset clearly shows significant trends in elevation-dependent temperature changes at the three transitions (Fig. 2), with stronger temperature increases at LGM-HTM, greater temperature decreases at HTM-LH and MCA-LIA at high elevation regions compared to low elevations, suggesting EDTA is a prevailed phenomenon in geological periods. Further, during the transition of LGM to HTM, the temperature increased by $3.8 \pm 1.2^{\circ} \mathrm{C}$ at sea level, while it increased by $8.1 \pm$ $1.2{ }^{\circ} \mathrm{C}$ (see Supplementary Methods for details on the calculation) at $3000 \mathrm{~m}$ a.s.1. as an example for alpine regions, based on the linear regression in Fig. 2. During the transition of HTM to LH, the temperature decreased by $0.8 \pm 0.9^{\circ} \mathrm{C}$ at sea level, while it decreased 
$1214.3 \pm 0.9^{\circ} \mathrm{C}$ in regions with elevations of $3000 \mathrm{~m}$ a.s.l. It is noteworthy that the

122 temperature amplification based on the various proxy indicators differs significantly at

123 high-elevation sites. Among all proxies, LCAs is ranked as the most sensitive proxy,

124 while the chironomidae as the least sensitive, which likely results from inherent response

125 of individual proxy to temperature variation (Fig. S3).

By grouping various proxy records together, we calculated temperature stacks at

different elevations by averaging the records (see Methods for details) and found that the

$\Delta T$ increased with elevation (Fig. S4). For example, during the transition of HTM-LH, $\Delta T$

increased from $0.7 \pm 0.1{ }^{\circ} \mathrm{C}$ at $0-1 \mathrm{~km}$ to $2.8 \pm 0.9{ }^{\circ} \mathrm{C}$ at elevation $>4 \mathrm{~km}$. Notably, the

Tibetan Plateau (averaged at $4500 \mathrm{~m}$ a.s.1.) experienced 2 3 times of temperature

during the three transitions. The amplitudes in EDTA are comparable to the modern

observations on the Tibetan Plateau ${ }^{18}$. Though EDTA at the three transitions represents

temperature variability at orbital, millennial $\left(0.8^{\circ} \mathrm{C} / 1000 \mathrm{yr}\right)$ and centennial scales

$\left(0.1^{\circ} \mathrm{C} / 100 \mathrm{yr}\right)$, the modern $\operatorname{EDW}\left(0.35^{\circ} \mathrm{C} / 10 \mathrm{yr}\right.$, annual mean temperature $)$ occurs 
141 using the mean annual temperature records with elevation gradients in the middle

142 latitudes of the Northern Hemisphere $\left(25-55^{\circ} \mathrm{N}\right)$, and obtained $\Gamma_{L G M}=-3.94 \pm$

$143 \quad 3.98^{\circ} \mathrm{C} / \mathrm{km}, \Gamma_{H T M}=-2.16 \pm 6.70^{\circ} \mathrm{C} / \mathrm{km}$, and $\Gamma_{L H}=-3.14 \pm 6.79^{\circ} \mathrm{C} / \mathrm{km}$, respectively $($ Fig.

144 3). It is not surprising that $\Gamma$ at the LGM, HTM and LH are smaller than the modern

145 average free-air $\Gamma$ value of $6.5^{\circ} \mathrm{C} / \mathrm{km}$ (the saturated adiabatic lapse rate) ${ }^{19}$, because the

146 air parcels unlikely follow the adiabatic processes strictly in a large area across 30

147 degrees in latitude. We calculated $\Gamma$ during $1970-2000\left(\Gamma_{\text {Modern }}\right)$ at the same locations as

148 the records, using the reanalysis temperature data in $\mathrm{WorldClim}^{20}$, the sea surface

149 temperature from HadISST1 ${ }^{21}$, and obtained $\Gamma_{\text {Modern }}=-2.26 \pm 4.30{ }^{\circ} \mathrm{C} / \mathrm{km}$. It is interesting

150 to observe that the $\Gamma_{L G M}$ is larger than $\Gamma_{\text {Modern, }}$, which agrees with the results of the

151 Kilimanjaro mountains ${ }^{16}$. The greater $\Gamma_{L G M}$ and smaller $\Gamma_{H T M}$ comparing with $\Gamma_{\text {Modern }}$

152 suggest that the high-elevation regions would be much colder during the LGM and

153 warmer during the HTM. This further supports the prevalence of EDTA in the past.

The EDTA at the three transitions also show clear zonal patterns (Fig. 4 and Fig.

$156 \mathrm{~S} 5)$. The $\Delta T$ for all proxy records were sub-grouped based on latitudes, including low

157 latitudes $\left(25^{\circ} \mathrm{S} \sim 25^{\circ} \mathrm{N}\right)$, middle $\left(25^{\circ} \mathrm{N} \sim 55^{\circ} \mathrm{N}\right)$, and high latitudes $\left(>55^{\circ} \mathrm{N}\right)$. During the

158 LGM-HTM transition, the strongest EDTA was observed for summer temperatures in

159 high latitudes (though the elevation of the highest record is only $720 \mathrm{~m}$ a.s.1.), followed

160 by relatively weak EDTA for summer and mean annual temperature in middle latitudes. 
161 The EDTA behave differently during the HTM-LH and MCA-LIA, with the strongest

162 EDTA for summer temperature in middle latitudes, followed by mean annual

163 temperatures in middle latitudes and summer temperatures in high latitudes (Fig. S5). The

164 patterns of EDTA based on climate records since LGM are quite different from modern

165 observations in alpine regions, with the strongest modern EDW for winter temperatures ${ }^{1}$.

166 The difference in the zonal patterns between past records and modern observations likely

167 results from 1) lack of sufficient winter temperature records since the LGM, 2) quite

168 different climate background between geological times and current global warming, and

169 3) different timescales from orbital, millennial- to interannual scales.

170

171 We calculated the $\Delta T$ from the TraCE-21ka simulation outputs across the world, in

172 order to compare with the EDTA revealed by the records. The model outputs capture the

173 polar amplifications very well, as exemplified in previous studies ${ }^{22,23}$, and the simulations

174 also reveal elevation-dependent temperature amplification to some extent (Fig. S6, S7).

175 The slight discrepancy in the elevation-dependent temperature variability between

176 climate reconstructions and TraCE-21ka models may result from 1) most proxy indicators

177 reveal near-surface or localized temperature variation, while the model performed the

178 temperature changes using a large spatial distribution CCSM3 simulation (T31_gx3v5

179 resolution $)^{24}$, and 2) the forcings affecting EDTA may not be fully addressed in the

180 models. 
The current EDW has been mainly attributed to snow-albedo feedback ${ }^{25,26}$, though multiple forcings, including cloud-radiation interactions ${ }^{27,28}$, water $\operatorname{vapor}^{29}$, aerosols ${ }^{30}$, anthropogenic black carbon, $\mathrm{CO}_{2}$ concentration $^{31}$ and underlying land cover estimate ${ }^{32}$ cannot be excluded. From the compilation of the quantitative terrestrial temperature reconstructions, the most evident EDTA in high latitudes at the transition of LGM-HTM, and in middle latitudes at HTM-LH likely suggest that the albedo may contribute to the occurrence of EDTA in high-elevation regions. During the transition of LGM-HTM, the high latitude regions experienced dramatic changes in glacier coverage at all elevations, which were mainly affected by orbital forcing and concentration of greenhouse gases. It 191 is not surprising that the summer temperature showed the most significant changes in high elevations due to changes in glacier albedo feedback. During the transition of HTM-

$193 \mathrm{LH}$, the summer temperature in middle latitudes revealed stronger EDTA, which would 194 be mainly affected by changes in vegetation-albedo feedback. Pollen-based 195 reconstruction for the Northern Hemisphere indicates the biome changed much more 196 significantly in the middle latitudes (ca. $46 \%$ of all available sites) than high latitudes 197 (approximately 25\% of all available sites) ${ }^{33}$ (Fig. S8), which was mainly affected by 198 movement of the Intertropical Convergence Zone driven by summer insolation. 199 Calculations of the effects of various forcings on temperature variability agree with our assumptions that greenhouse gases and ice sheet variation dominate orbital scale ${ }^{34}$, and 
201 orbital-driven insolation variations contributes mostly to millennial scale during

202 Holocene (Fig. S9).

203

204 Summary

205 Syntheses of quantitative temperature records since the Last Glacial Maximum

206 indicate that the Elevation-Dependent Temperature Amplification (EDTA) in alpine

207 regions across the world not only occurs in the context of current global warming, but

208 was also relevant in geological periods. The high-elevation regions were much colder

209 during glacial periods, and much warmer during interglacial periods than previously

210 thought. The reasons might be attributed to the changes in land surface albedo related to

211 glacier and vegetation coverage.

212 This has implications for paleoclimate studies, which requires in-depth

213 understanding of alpine climate changes. The rate of the current warming in high

214 elevation regions, in the context of anthropogenic global change, is likely much faster

215 than that in the geological periods, indicating that the alpine regions may face much

216 faster warming in the near future. This forces us to reassess whether the $2{ }^{\circ} \mathrm{C}$ projection is

217 appropriate for high elevation environments in the context of current global warming.

218 Policy makers need to reevaluate the mitigation and adaptation strategies in alpine

219 regions under the high greenhouse gas emissions scenario.

220 
221 Acknowledgments: The work was supported by National Natural Science Foundation of

222 China (42025103, 41772178, 91747207, 42001084, 41620104007), the Pan-Third Pole

223 Environment Study for a Green Silk Road of CAS Strategic Priority Research Program

224 (XDA20090000), the National Key R\&D Program of China (2018YFA0606400). E.X.

225 acknowledges support by the Academy of Athens and the Greek "National Research

226 Network on Climate Change and its Impact" (project code 200/937) and the German

227 Federal Ministry of Education and Research (BMBF) projects NUKLEUS and

228 ClimXtreme.

229

230 Author contributions: J.H., F.L. and F.C. designed the research; J.H., F.L., Z.S., K.Y.,

231 X.H., M.D., W.D. performed the data analysis; J.C. performed the model simulation; X.C.

232 performed biome reconstruction. E.X. and J.L. improved the manuscript with

233 constructive comments and suggestions. F.L., J.H., E.X. and F.C. led the writing of the

234 paper and all authors contributed to the interpretation of the results and to the text.

235

236 Competing interests: Authors declare no competing interests.

238 Data and materials availability: All data and methods needed to evaluate the

239 conclusions in this paper are present in the Supplementary Materials. 


\section{References}

2421 Pepin, N. et al. Elevation-dependent warming in mountain regions of the world.

$243 \quad$ Nature Climate Change 5, 424-430 (2015).

2442 IPCC. Global Warming of $1.5^{\circ} \mathrm{C}$ : An IPCC Special Report on the impacts of

245 global warming of $1.5^{\circ} \mathrm{C}$ above pre-industrial levels and related global

246 greenhouse gas emission pathways, in the context of strengthening the global

247 response to the threat of climate change, sustainable development, and efforts to

248 eradicate poverty. [Masson-Delmotte, P. Zhai, H. O. Pörtner, D. Roberts, J. Skea,

249 P.R. Shukla, A. Pirani, W. Moufouma-Okia, C. Péan, R. Pidcock, S. Connors, J. B.

250 R. Matthews, Y. Chen, X. Zhou, M. I. Gomis, E. Lonnoy, T. Maycock, M. Tignor, T.

251 Waterfield (eds.) ]. In Press (2018).

2523 Palazzi, E., Filippi, L. \& Hardenberg, J. V. Insights into elevation-dependent

253 warming in the Tibetan Plateau-Himalayas from CMIP5 model simulations.

254 Climate Dynamics 48, 3991-4008 (2017).

2554 Duan, A. \& Xiao, Z. Does the climate warming hiatus exist over the Tibetan

$256 \quad$ Plateau? Scientific reports 5, 13711 (2015).

2575 You, Q. et al. Elevation dependent warming over the Tibetan Plateau: Patterns,

258 mechanisms and perspectives. Earth-Science Reviews 210, 103349,

259 doi:https://doi.org/10.1016/j.earscirev.2020.103349 (2020).

2606 Duan, J. et al. Weakening of annual temperature cycle over the Tibetan Plateau 

(2017).

2637 Kääb, A. et al. Massive collapse of two glaciers in western Tibet in 2016 after surge-like instability. Nature Geoscience 11, 114-120, doi:10.1038/s41561-0170039-7 (2018).

2668 Immerzeel, W. W. et al. Importance and vulnerability of the world's water towers. Nature 577, 364-369, doi:10.1038/s41586-019-1822-y (2020).

2689 Pritchard, H. D. Asia’s shrinking glaciers protect large populations from drought stress. Nature 569, 649-654, doi:10.1038/s41586-019-1240-1 (2019).

$27010 \quad$ Clark, P. U. et al. Global climate evolution during the last deglaciation.

$271 \quad$ Proceedings of the National Academy of Sciences 109, E1134-E1142 (2012).

27211 Routson, C. C. et al. Mid-latitude net precipitation decreased with Arctic warming

273 during the Holocene. Nature 568, 83-87, doi:10.1038/s41586-019-1060-3 (2019).

27412 Kaufman, D. et al. A global database of Holocene paleotemperature records.

275 Scientific data 7, 115, doi:10.1038/s41597-020-0445-3 (2020).

27613 Marcott, S. A., Shakun, J. D., Clark, P. U. \& Mix, A. C. A reconstruction of regional and global temperature for the past 11,300 years. Science 339, 11981201, doi:10.1126/science.1228026 (2013). the Common Era. Scientific data 4, 170088, doi:10.1038/sdata.2017.88 (2017). 
28115 Rehfeld, K., Münch, T., Ho, S. L. \& Laepple, T. Global patterns of declining temperature variability from the Last Glacial Maximum to the Holocene. Nature 554, 356, doi:10.1038/nature25454 (2018).

16 Loomis, S. E. et al. The tropical lapse rate steepened during the Last Glacial Maximum. Science Advances 3, e1600815 (2017).

17 Whitehead, J. A. \& Clift, P. D. Continent elevation, mountains, and erosion: Freeboard implications. Journal of Geophysical Research: Solid Earth 114 (2009). and Water Cycle Intensification and Interactions between Monsoon and doi:10.1175/BAMS-D-17-0057.1 (2019). lapse rates from the northern to the southern slopes of the Himalayas. International Journal of Climatology 35, 4431-4443, doi:10.1002/joc.4297 (2015).

Fick, S. E. \& Hijmans, R. J. WorldClim 2: new 1-km spatial resolution climate surfaces for global land areas. International Journal of Climatology 37, 43024315, doi:https://doi.org/10.1002/joc.5086 (2017). 
30121 Rayner, N. A. et al. Global analyses of sea surface temperature, sea ice, and night

302 marine air temperature since the late nineteenth century. Journal of Geophysical

303 Research: Atmospheres 108, doi:https://doi.org/10.1029/2002JD002670 (2003).

30422 Masson-Delmotte, V. et al. Past and future polar amplification of climate change:

305 climate model intercomparisons and ice-core constraints. Climate Dynamics 26,

$306 \quad 513-529$, doi:10.1007/s00382-005-0081-9 (2005).

30723 Russotto, R. D. \& Biasutti, M. Polar Amplification as an Inherent Response of a

308 Circulating Atmosphere: Results From the TRACMIP Aquaplanets. Geophysical

$309 \quad$ Research Letters 47, doi:10.1029/2019g1086771 (2020).

31024 Liu, Z. et al. Transient simulation of last deglaciation with a new mechanism for

311 Bølling-Allerød warming. Science 325, 310-314 (2009).

31225 Zhang, Y. et al. Light-absorbing impurities enhance glacier albedo reduction in

313 the southeastern Tibetan Plateau: Light-absorbing impurities in snow. Journal of

314 Geophysical Research Atmospheres 122, 6915-6933 (2017).

31526 Rhoades, A. M., Ullrich, P. A. \& Zarzycki, C. M. Projecting 21st century

316 snowpack trends in western USA mountains using variable-resolution CESM.

317 Climate Dynamics 50, 261-288, doi:10.1007/s00382-017-3606-0 (2018).

31827 Kuang, X. \& Jiao, J. J. Review on climate change on the Tibetan Plateau during

319 the last half century. Journal of Geophysical Research Atmospheres 121, 3979-

$320 \quad 4007(2016)$ 
32128 Zhang, X. Q., Peng, L. L., Zheng, D. \& Tao, J. Cloudiness variations over the

322 Qinghai-Tibet Plateau during 1971-2004. Journal of Geographical Sciences 18,

323 142-154, doi:10.1007/s11442-008-0142-1 (2008).

32429 Rangwala, I., Miller, J. R. \& Ming, X. Warming in the Tibetan Plateau: possible

325 influences of the changes in surface water vapor. Geophysical Research Letters

$326 \quad 36,295-311(2009)$.

$32730 \quad$ Lau, W. K. M., Kim, M. K., Kim, K. M. \& Lee, W. S. Enhanced surface warming

328 and accelerated snow melt in the Himalayas and Tibetan Plateau induced by

329 absorbing aerosols. Environmental Research Letters 5, 025204 (2010).

33031 Chen, B., Chao, W. C. \& Liu, X. Enhanced climatic warming in the Tibetan

331 Plateau due to doubling CO2: a model study. Climate Dynamics 20, 401-413

$332 \quad$ (2003).

$333 \quad 32$ Cui, X. \& Graf, H. F. Recent land cover changes on the Tibetan Plateau: a review.

334 Climatic Change 94, 47-61 (2009).

33533 Cao, X., Tian, F., Dallmeyer, A. \& Herzschuh, U. Northern Hemisphere biome

$336 \quad$ changes $\left(>30^{\circ} \mathrm{N}\right)$ since $40 \mathrm{cal} \mathrm{ka} \mathrm{BP}$ and their driving factors inferred from

337 model-data comparisons. Quaternary Science Reviews 220, 291-309 (2019).

33834 Shakun, J. D. et al. Global warming preceded by increasing carbon dioxide

339 concentrations during the last deglaciation. Nature 484, 49-54,

340 doi:10.1038/nature10915 (2012). 
Figure 1

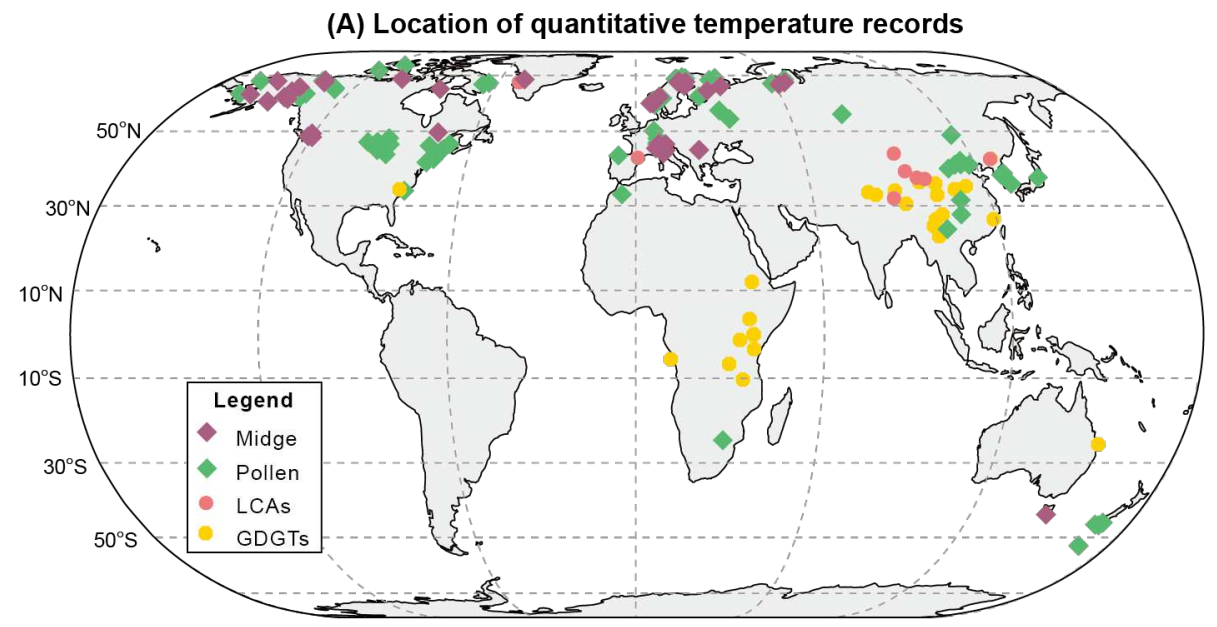

(B) Distribution of records

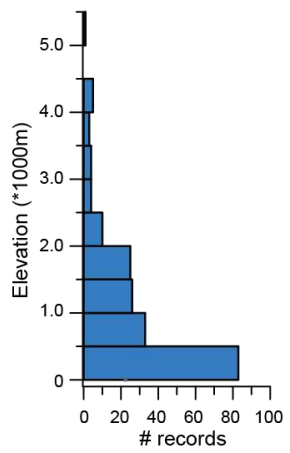

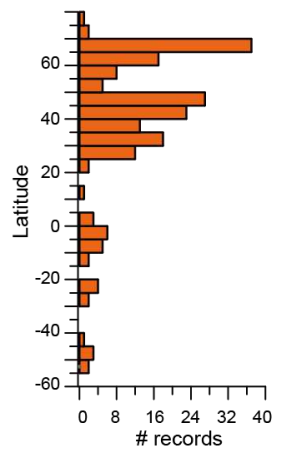

(C) Temporal availability of the records

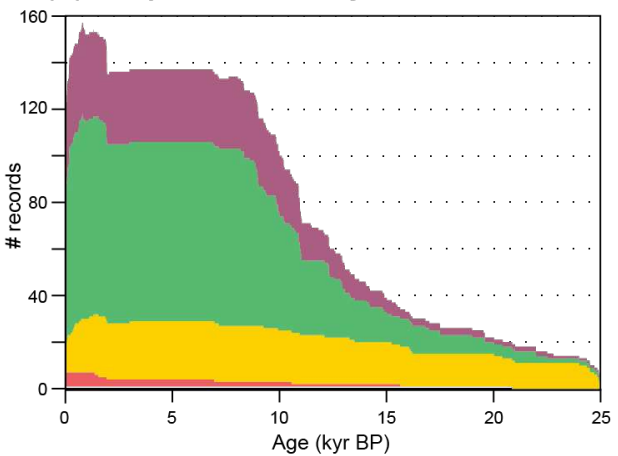

Figure 1. Spatiotemporal distribution of terrestrial temperature records since LGM.

(A) Map showing the locations of the temperature records based on GDGTs, LCAs, pollen and midge proxy indicators. (B) Distribution of the records by elevations in $0.5 \mathrm{~km}$ intervals (left) and by latitude in $5^{\circ}$ steps (Right). (C) Temporal availability of temperature records based on proxy indicators. LCAs represents long-chain alkenones, GDGTs stands for glycerol dialkyl glycerol tetraethers. 
Figure 2

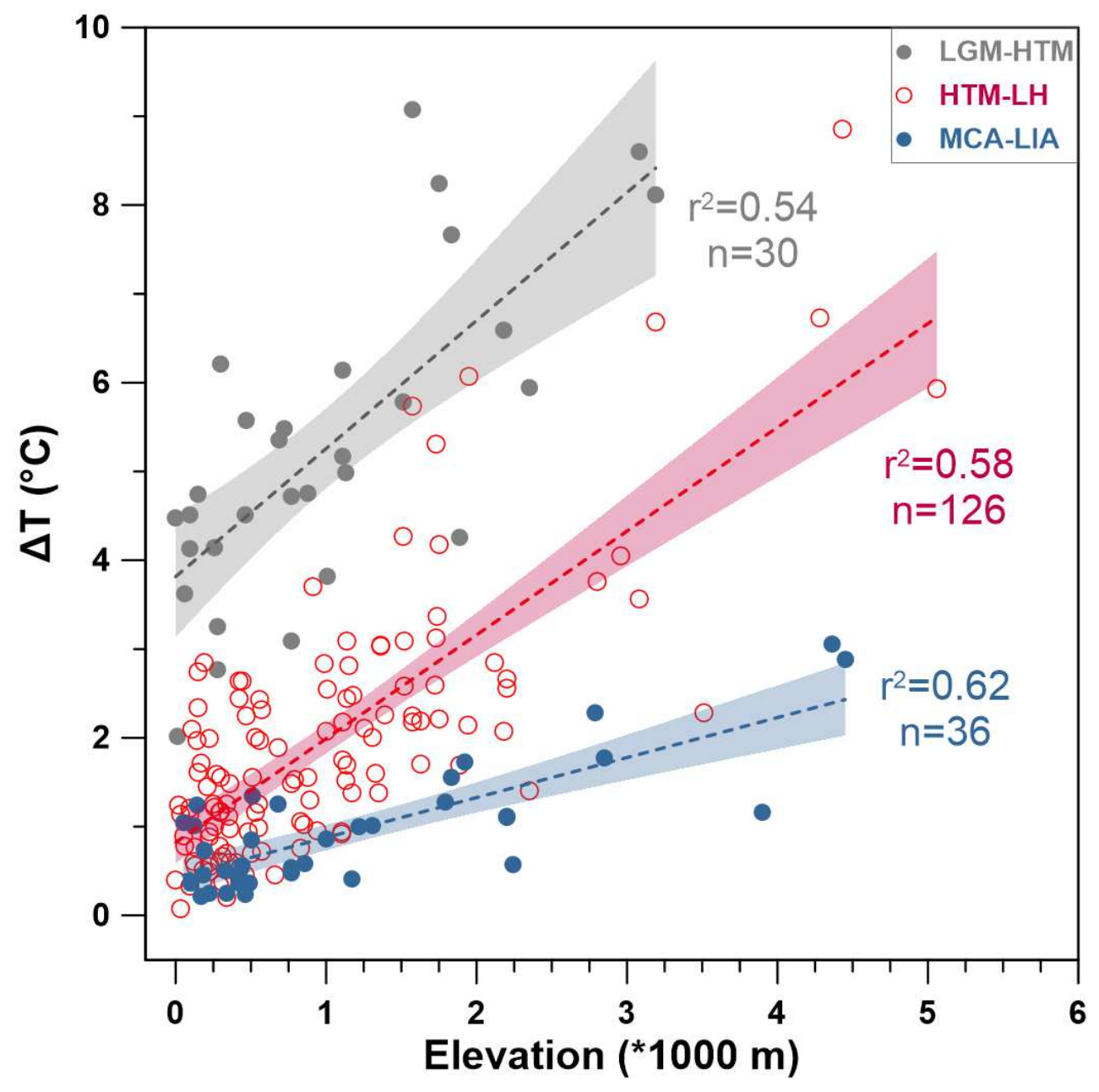

Figure 2. Dependence of temperature changes on elevation around the world across records were sub-grouped at important climate transitions of LGM-HTM (solid circles in grey), HTM-LH (open circles in red), and MCA-LIA (solid circles in blue). Shading represents $95 \%$ bootstrap confidence intervals with 5000 replicates. 
Figure 3. HadISST1.

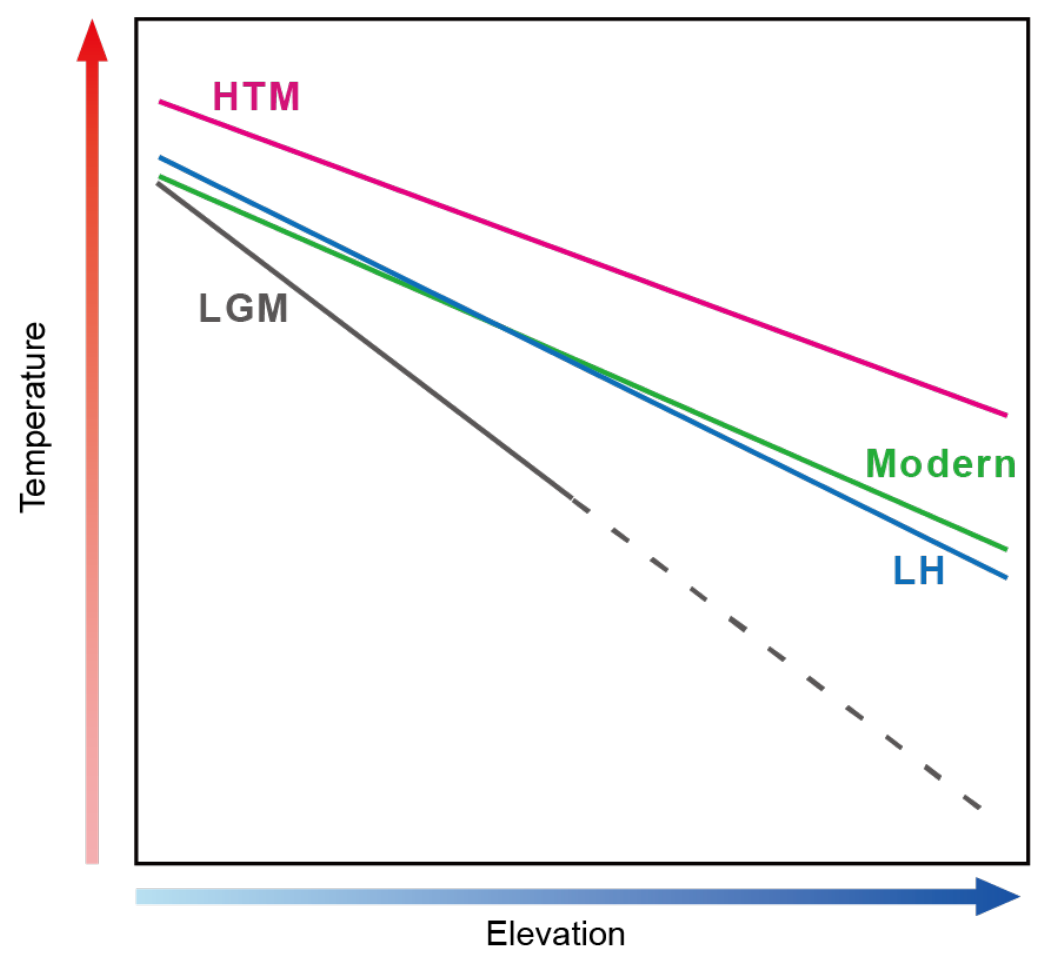

Figure 3. Schematic comparison of the lapse rate for the mean annual temperatures in the middle latitudes of the Northern Hemisphere $\left(25-55^{\circ} \mathrm{N}\right)$ at LGM, HTM, LH

and Modern. Solid and dash lines in grey represent the lapse rate at LGM, solid line in pink represents lapse rate at HTM, solid line in blue for LH, solid line in green for modern. As the highest record during LGM goes back to $3194 \mathrm{~m}$ a.s.1., the lapse rate was linearly extended to higher elevation for comparison. The modern lapse rate was calculated at the same locations for the records for the periods of 1970-2000 AD, using the reanalysis temperature data in WorldClim and the sea surface temperature from 
$375 \quad$ Figure 4

376
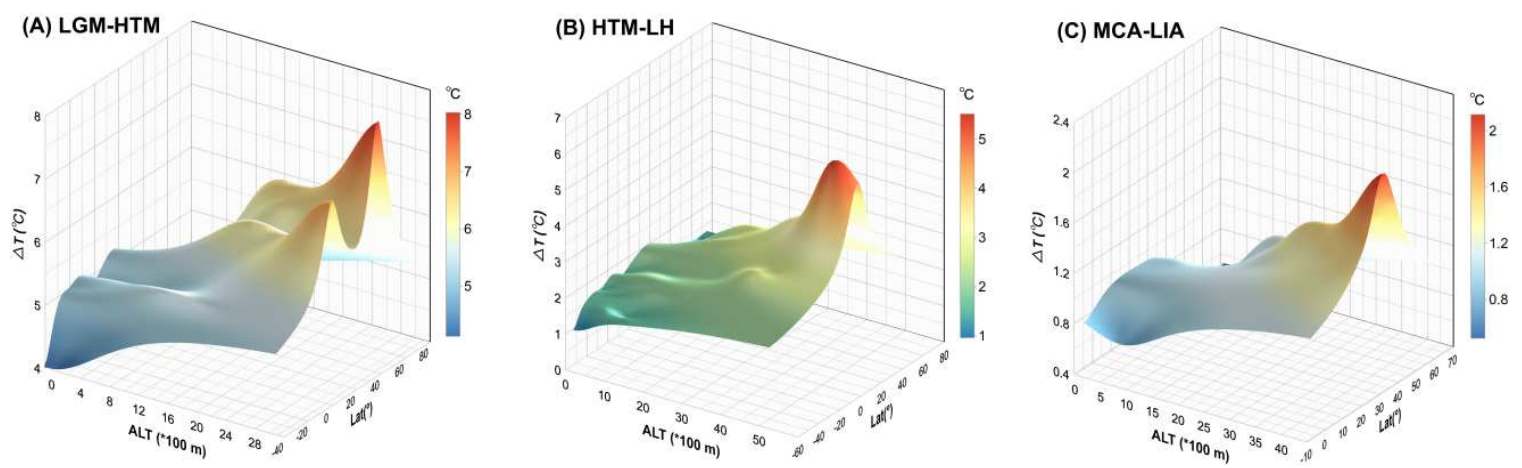

Figure 4. 3-D view of variability of temperature changes versus elevations and

381 Note that amplitudes of temperature changes vary with elevation and latitudes at three transitions (see details in Fig. S5). 


\section{Supplementary Files}

This is a list of supplementary files associated with this preprint. Click to download.

- S2EDTASupData220210727.xlsx

- S1EDTASupData120210727.xlsx 